\title{
ERRATUM
}

\section{Cost-Effectiveness of Transcranial Magnetic Stimulation in the Treatment of Major Depression: a Health Economics Analysis}

Kit N. Simpson · Mary Jane Welch · F. Andrew Kozel · Mark A. Demitrack · Ziad Nahas

(c) Springer Healthcare Communications 2009

In the article by Kit N. Simpson and colleagues entitled 'Cost-Effectiveness of Transcranial Magnetic Stimulation in the Treatment of Major Depression: a Health Economics Analysis', published in Advances in Therapy 2009 Mar;26(3):346-368, the following corrections should be made for Figure 3 (A, B, C, and D):

- The horizontal axis label should be 'TMS cost per treatment session'

- The vertical axis scale should be $14,000,12,000, \ldots, 2000,0,-2000, \ldots,-10,000,-12,000$

The correct figure should appear as follows:

Figure 3. Savings (costs) per patient per year treated with TMS compared with pharmaceutical antidepressant standard care. (A) Randomized, controlled Study 101, overall study population $n=301$; (B) Randomized, controlled Study 101, ATHF=1 study population only $n=164$; (C) Open-label Study 102, overall study population $n=301$; (D) Open-label Study 102, ATHF $=1$ study population only $n=164$. ( ) With and ( $)$ without productivity gains included in model.

(A)

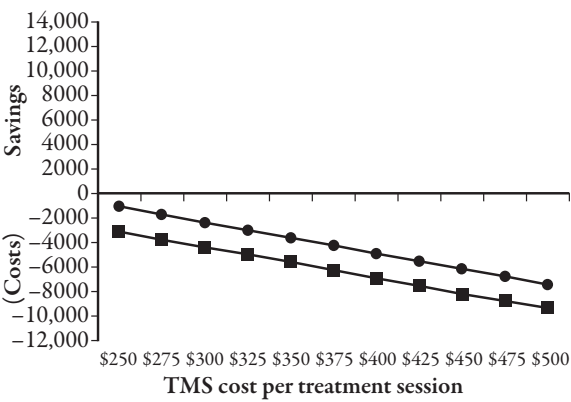

(C)

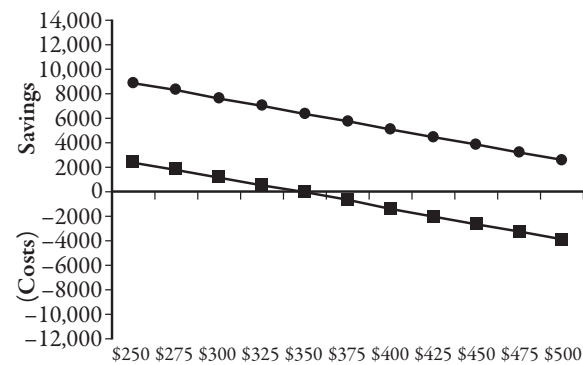

TMS cost per treatment session
(B)

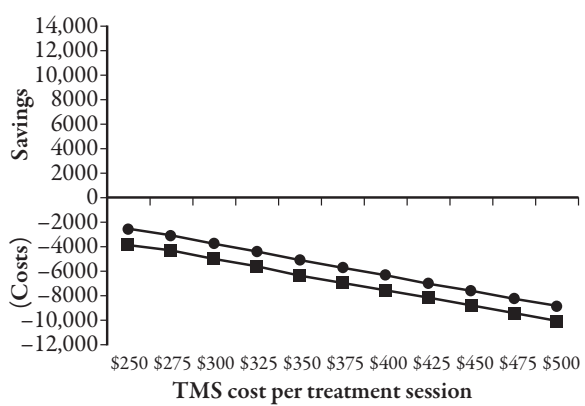

(D)

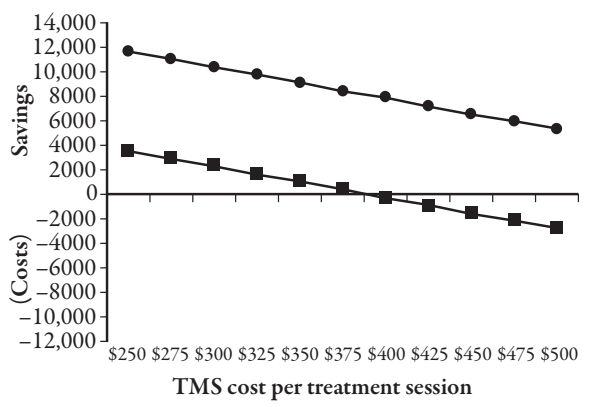

